\title{
U.S. Geological Survey Shrub/Grass Products Provide New Approach to Shrubland Monitoring
}

4

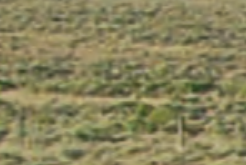

and

chenchotises

H.

(6)

- Thestin

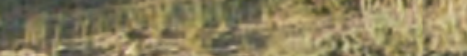

25 
In the Western United States, shrubland ecosystems provide vital ecological, hydrological, biological, agricultural, and recreational services. However, disturbances such as livestock grazing, exotic species invasion, conversion to agriculture, climate change, urban expansion, and energy development are altering these ecosystems (fig. 1).

Improving our understanding of how shrublands are distributed, where they are changing, the extent of the historical change, and likely future change directions is critical for successful management of these ecosystems. Remote-sensing technologies provide the most likely data source for large-area monitoring of ecosystem disturbance — both near-real time and historically. A monitoring framework supported by remote-sensing data can offer efficient and accurate analysis of change across a range of spatial and temporal scales.

The U.S. Geological Survey (USGS) has been working to develop new remote-sensing data, tools, and products to characterize and monitor these changing shrubland landscapes. Nine individual map products (components) have been developed that quantify the percent of shrub, sagebrush, big sagebrush, herbaceous, annual herbaceous, litter, bare ground, shrub height, and sagebrush height at 1-percent intervals in each 30-meter grid cell (fig. 2). These component products are designed to be combined and customized to widely support different applications in rangeland monitoring, analysis of wildlife habitat, resource inventory, adaptive management, and environmental review.
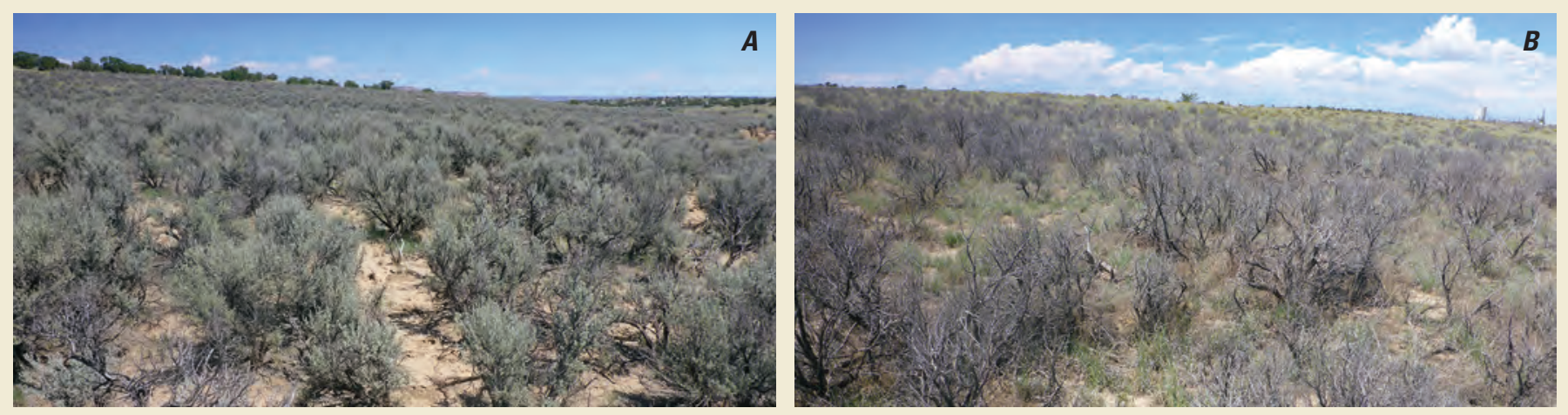

Figure 1. Shrubland change is common across the Western United States and is a main focus of the U.S. Geological Survey shrubland mapping project. The landscapes in these images in northwest New Mexico are roughly 1 kilometer apart and demonstrate $A$, a sagebrush dominant landscape as compared to $B$, a degraded sagebrush landscape with increasing herbaceous cover.

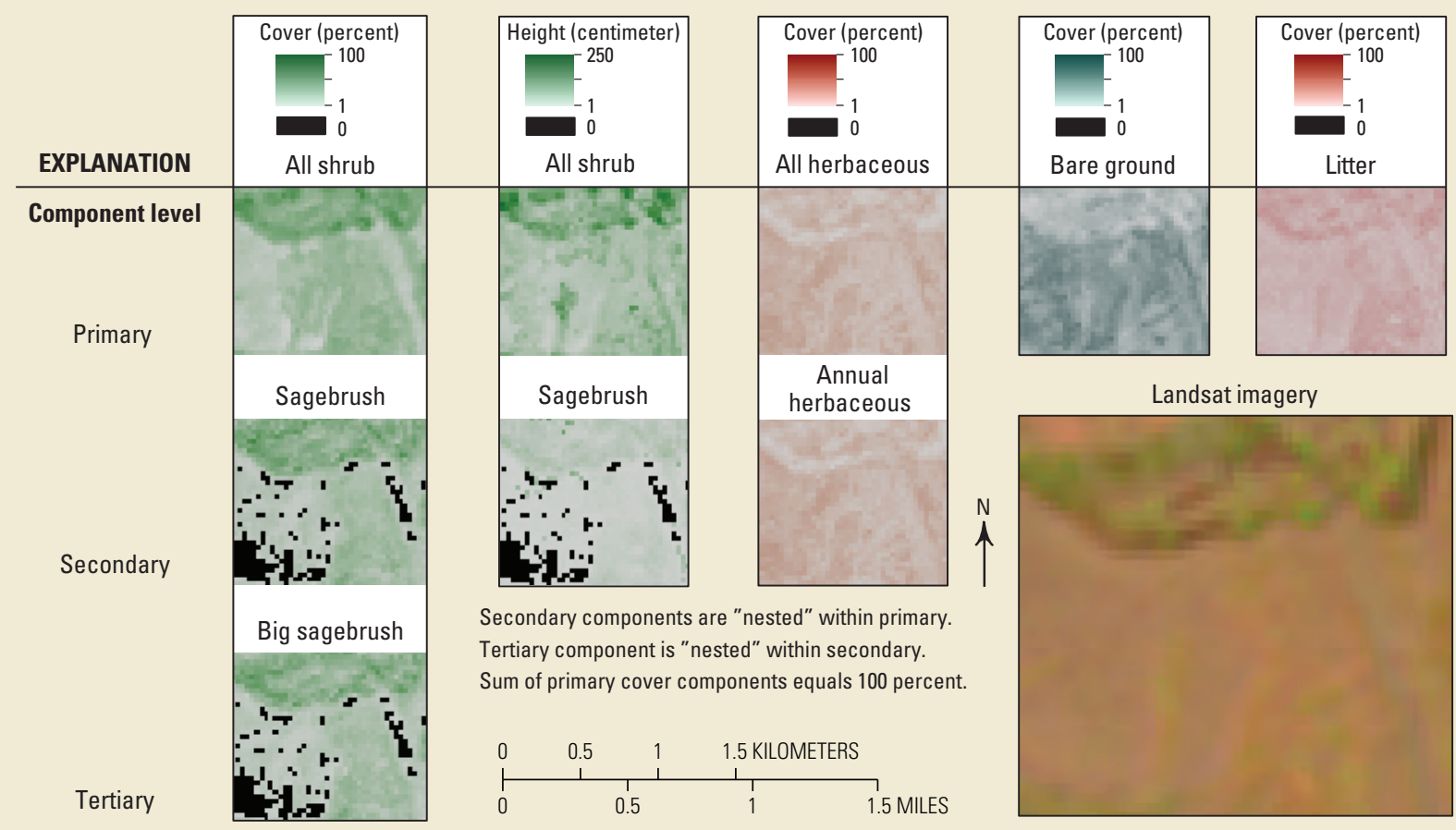

Figure 2. Mapped shrubland components, sorted by their hierarchical level. Component groups are contained by black boxes. For example, within the all shrub primary component group, sagebrush is secondary, and big sagebrush is tertiary. So big sagebrush cover and extent is never greater than sagebrush. Similarly, sagebrush cover and extent is never greater than all shrub cover. The sum of primary cover components (all shrub, all herbaceous, bare ground, and litter) is 100 percent in a typical rangeland environment. Pixels with zero percent cover or height for each component are depicted in black pixels. 


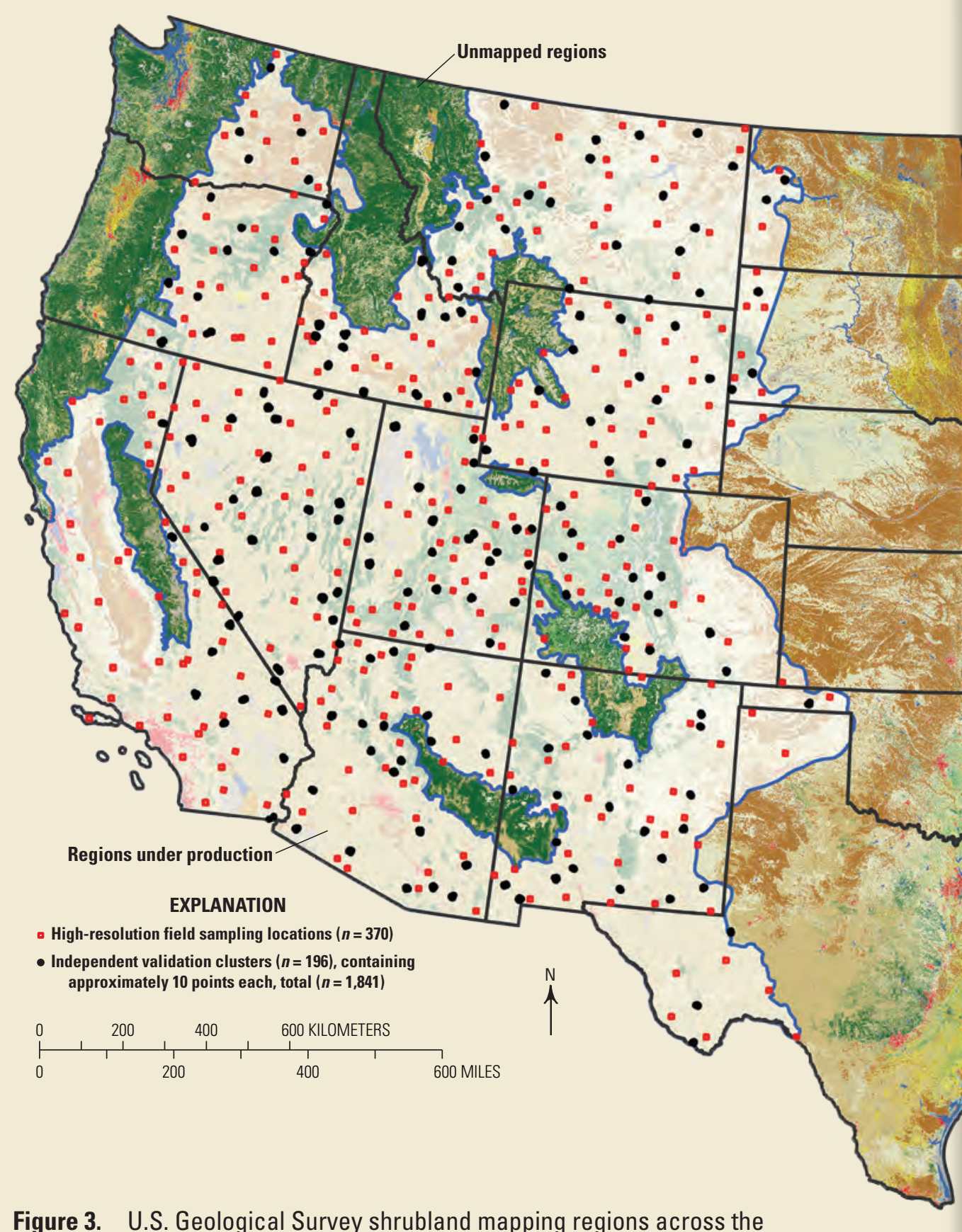

Figure 3. U.S. Geological Survey shrubland mapping regions across the Western United States.

\section{Managing Landscapes with a Landscape Lens}

Component shrubland products offer land managers and scientists an entirely new way to approach landscape management and monitoring. These new products fractionally characterize current and historical vegetation cover across broad landscapes and monitor changes among shrubs and grasses. These new data products also will help land managers think beyond the one-parcel, one-decision approach by simultaneously providing access to a new and more complete understanding of ecosystem-scale components, while still retaining most of the local patch detail essential for applying day-to-day management decisions.

These component products are being created by the USGS Shrub/Grass Mapping Project as a collaborative venture with the Bureau of Land Management (fig. 3). Additional collaboration is also provided by the Multi-Resolution Land Characteristics Consortium - a group of Federal agencies that coordinate and generate consistent and relevant national-scale land cover information. These products will ultimately be available for most shrubland regions of the Western United States, and once completed will offer the most comprehensive remote sensing-based quantification of Western U.S. shrublands to date.

\section{Product Characteristics}

The USGS developed several new innovative methods to create these component products, some of which include the following:

- Tasking high-resolution (2-meter pixels) Worldview (WV) satellites for selected sample sites to collect imagery when vegetation phenology was best for mapping. Field crews ground-sampled these sites roughly the same time as the satellite collected the image to ensure optimal measurement. These field measurements were then applied through a regression tree to create a separate map for each component at a 2-meter scale.

- Scaling up these 2-meter WV products to the landscape level by integrating them with multiple Landsat satellite images ( 30 meters) and ancillary data with regression-tree software to provide wall-to-wall 30-meter component predictions across the landscape.

- Providing three kinds of product validation, including validation from independent field measurements, cross validation from regression-tree models, and spatial error maps, which are product deliverables that spatially quantify mapping accuracies.

Beyond just developing a new set of base products, this fractional component approach is designed to support better monitoring of change across time. Remote-sensing images interpreted into fractional components offer a way to measure both abrupt changes from fire and human disturbance, and gradual change from grazing, invasive species, and climate change (fig. 4). 


\section{Quantifying Historical Change Through the Landsat Archive}

Once a base shrubland component product has been produced for the current year, historical component predictions can then be created for previous years. These predictions depend on Landsat 30-meter imagery from an archive containing images back to 1984. In an effort to exploit this archive, the USGS developed new analytical methods to enable historical quantification of component change in shrubland ecosystems since 1984 . These methods rely on a change vector analysis approach that scrutinizes historical imagery for any spectral change from the present year. When a spectral change is determined, unchanged areas from the present year are used to provide training data to update the component predictions in historically changed areas. This approach allows classification of historical imagery with training data from the present year. Analysis of these product results has shown success at detecting gradual change processes such as climate change and grazing.

The USGS has operationalized this approach, and is now producing back-intime analysis for large regions of the Western United States. Once completed, this analysis of change across time from 1984 through 2017 for each component product will provide critical information for resource managers and scientists regarding how much these landscapes have historically changed, and when and where that change happened.

\section{Telling the Monitoring Story of Every Western Pixel}

The long-term goal of this USGS research effort is to tell the story through time of every pixel (a 30-meter-square parcel of land) across the shrubland landscapes of the Western United States. We plan to accomplish this by measuring, mapping, monitoring, and analyzing results for shrubland vegetation. We plan to address:

- What was the pixel in 1984;

- What is the pixel now;

- If it changed since 1984, what changed it;

- How will the pixel likely change in the future?

Work is in progress to compare these historical component change observations to climate data, wildfire occurrences, historical grazing records, and other management data to analyze the cause of changes, and attempt to project where and when similar changes may occur in the future.

As these remote-sensing shrub/grass products become widely available throughout the West, they will provide a wealth of understanding on the current extent of shrub and grasslands, insight into what is driving change, and better understanding of how they will change in the future.

A planned application of these products is to provide long-term monitoring of shrub landscapes. Hence, as new satellite imagery is collected, it will be possible to annually monitor these landscapes for change. As future change is measured, it will increase our understanding of when, where, and how much change is occurring, and ultimately promote better science and more informed shrubland ecosystem management.

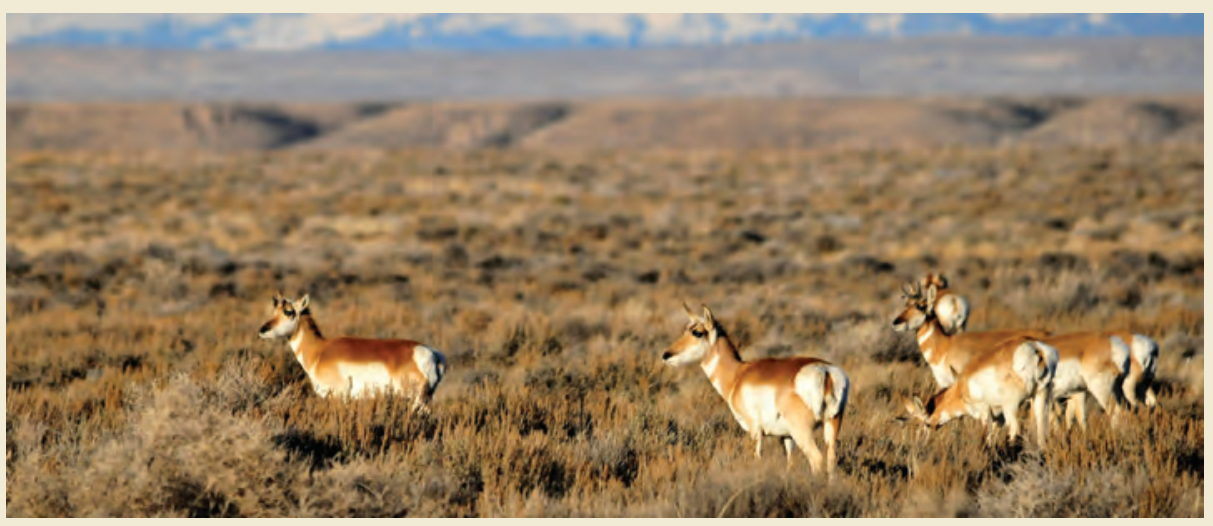

Pronghorns eating Wyoming big sagebrush with the Wind River Mountain Range in Wyoming as a backdrop. Photograph by Tom Koerner, U.S. Fish and Wildlife Service.

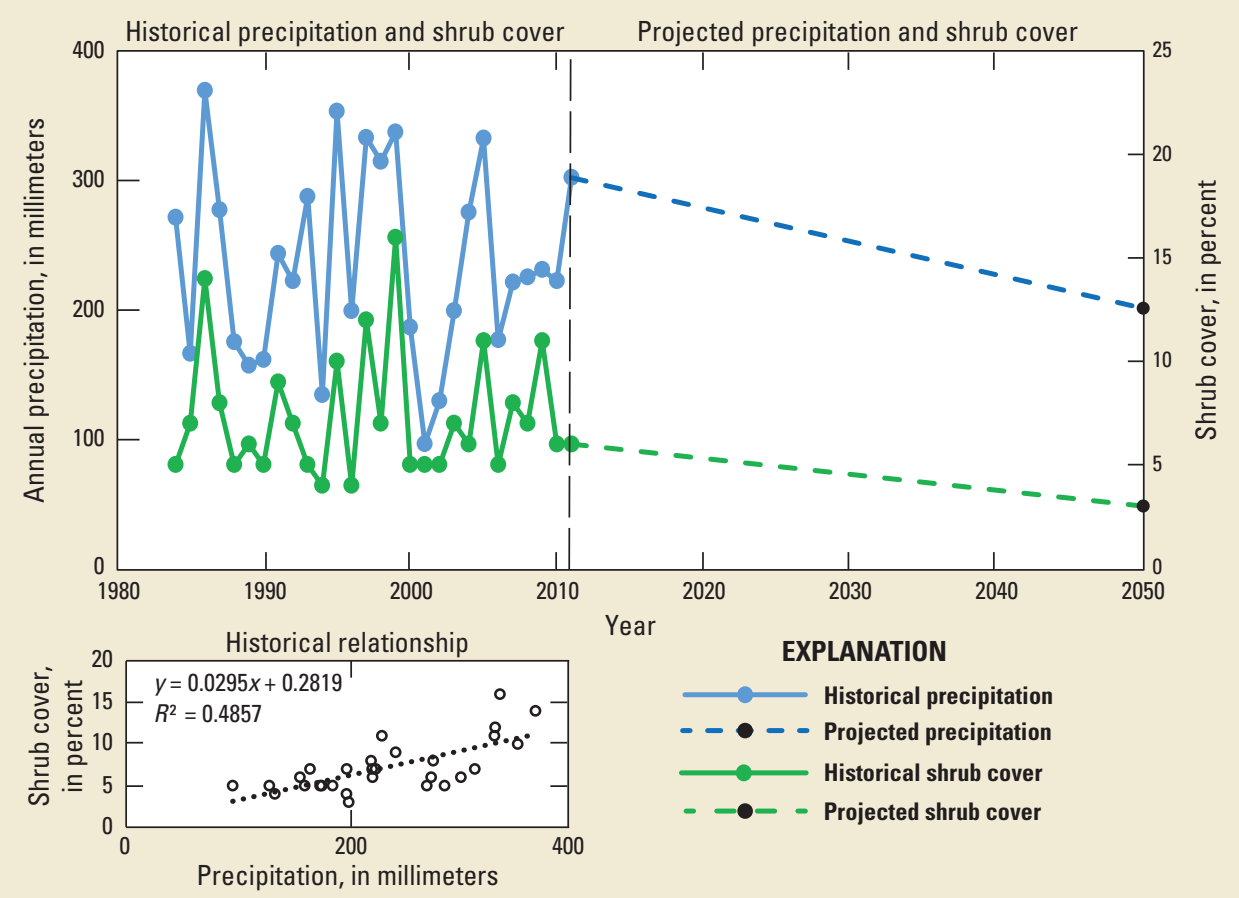

Figure 4. Relationship between annual and historical precipitation and shrub cover interpreted from remote-sensing images. With projected declining precipitation, shrub cover density will likely decline.

\section{For additional information concerning this publication, contact:}

Director, USGS Earth Resources Observation and Science (EROS) Center

Or visit the EROS Center website at: 47914 252nd Street

Sioux Falls, SD 57198 https://eros.usgs.gov

(605) 594-6151

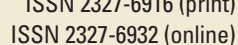
https://doi.org/10.3133/fs20173084 